\title{
Development of Propolis (Apis trigona)-loaded Nanoemulgel for Improved Skin Penetration of Caffeic Acid: The Effect of Variation of Oleic Acid Concentration
}

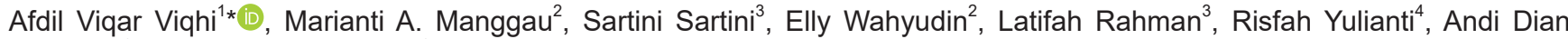 \\ Permana $^{3}$, Satria Aztasaury Awal ${ }^{1}$ \\ ${ }^{1}$ Postgraduate, Faculty of Pharmacy, Hasanuddin University, Makassar, South Sulawesi, Indonesia; ${ }^{2}$ Department of \\ Pharmacology and Toxicology, Faculty of Pharmacy, Hasanuddin University, Makassar, South Sulawesi, Indonesia; ${ }^{3}$ Department \\ of Pharmaceutics, Faculty of Pharmacy, Hasanuddin University, Makassar, South Sulawesi, Indonesia; ${ }^{4}$ Department of \\ Chemical Pharmacy, Faculty of Pharmacy, Hasanuddin University, Makassar, South Sulawesi, Indonesia
}

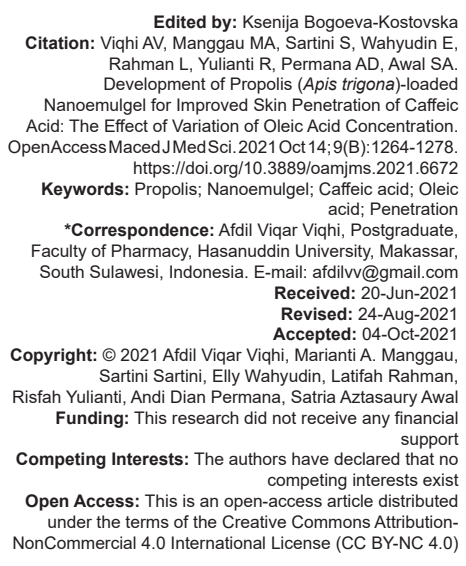

NonCommercial 4.0 International License (CC BY-NC 4.0)

\begin{abstract}
BACKGROUND: Propolis contains caffeic acid compounds, which are proven to have pharmacological effects as an anti-inflammatory. However, its effectiveness is hampered by the poor solubility of caffeic acid. Here, we report developing the nanoemulgel approach containing propolis extract as an active ingredient and oleic acid as a permeation enhancer for transdermal delivery of caffeic acid.
\end{abstract}

AIM: This study aims to determine the effect of oleic acid concentration on increasing caffeic acid permeation in the skin and obtain a nanoemulgel formula with desired physical characteristics and stability.

MATERIALS AND METHODS: Propolis was macerated with $70 \%$ ethanol; the total phenolic content was measured by ultraviolet-visible spectrophotometer, and the levels of caffeic acid in the extracts and nanoemulgel preparations were finally determined using ultra-fast liquid chromatography. Formulas were made using various concentrations of oleic acid, namely, 1.25\%w/w (Formula F1); $2.5 \% \mathrm{w} / \mathrm{w}$ (Formula F2); 5\%w/w (Formula F3), respectively; and $1.25 \% \mathrm{w} / \mathrm{w}$ without propolis extract (Formula F4) as a comparison.

RESULTS: The results obtained from analysis of variance statistical exhibited that the difference in oleic acid concentrations in four formulas significantly affected $(p<0.05)$ particle size, polydispersity index, spreadability, adhesion, freeze-thaw, permeation, and retention test. However, there was no significant difference $(p>0.05)$ on $\mathrm{pH}$ and viscosity before and after 4 weeks of storage and zeta potential test. The highest amount of permeation and retention was found in F3 and F2, respectively, and all formulas tended to follow zero-order drug release kinetics. Furthermore, the results showed that the number of percent's permeated in a row was $3.74 \%$ (F1); $5.58 \%$ (F2); $11.67 \%(F 3)$, and F2 was the formula with the most optimal retention amount with a percentage of $43.13 \%$ at $24 \mathrm{~h}$.

CONCLUSION: This study shows a promising delivery system for increasing the effectiveness of natural lipophilic compounds to treat inflammation in the skin.

\section{Introduction}

Propolis is a natural resin product that bees collect from several plants and mix with beeswax and salivary enzymes ( $\beta$-glucosidase); this complex mixture of compounds is also called bee glue [1]. Propolis is obtained from various plants, especially from the buds, leaves, plant shoots, exudates, and other parts of plants [2]. The main components contained in propolis are flavonoids, terpenoids, cinnamic acid, caffeic acid, and various esters [3], which have critical pharmacological properties such as immunomodulator, antitumor, anti-inflammatory, antioxidant, antiviral, antiparasitic [1], [4], bacteriostatic, and bactericidal agents among many other uses [5], [6].

Caffeic acid (3,4-dihydroxycinnamic) in propolis has been shown to have anti-inflammatory properties with an inhibitory mechanism of action on myeloperoxidase activity, NADPH oxidase ornithine decarboxylase, tyrosine-protein-kinase, and hyaluronidase from mast cells [7], [8]. In addition, the anti-inflammatory properties of caffeic acid are due to the inhibition of 5- and 12-lipooxygenase activity [9]. However, caffeic acid compounds are often limited in their delivery to the skin because they are influenced by the lipophilicity of these compounds [10]. Therefore, a more effective topical formulation is needed. Several studies of nano-based caffeic acid such as nanoencapsulations, nanoparticles, nanoemulsions, and other lipid nanocarriers have been carried out [11], [12], [13], [14]. The application of nanoemulsion technology has been increasingly applied as an effective topical drug carrier, has many benefits in various applications due to its characteristic properties, small droplet size (in the range of $20-500 \mathrm{~nm}$ ) with the high interfacial area, high storage stability, low preparation 
cost, thermodynamic stability, transparent appearance, high solubilization capacity, low viscosity, high kinetic, sedimentation stability, flocculation, and in some cases coalescence [15], [16], [17]. Such systems can be used for transdermal penetration of lipophilic drugs due to their high drug loading capacity and increased permeability without causing skin irritation [15]. Nanoemulsions become a promising alternative to enhance penetration of drug delivery systems and target drugs less soluble by increasing its absorption through the skin, better drug retention time at the target area, and thus producing fewer side effects [18]. Nanoemulsion formula is not convenient to use because of its low viscosity and poor dispersion. Therefore, the approach of combining nanoemulsions with gelling systems can help overcome this problem [19]. Nanoemulgel, known as hydrogel-based nanoemulsion formation, adds a nanoemulsion system integrated into the hydrogel matrix, which affects better skin penetration [20]. The topical penetrating nanoemulgel formula acts as a drug reservoir, influencing drug release from the inner phase to the outer stage and further into the skin. The nanoemulgel onto the skin releases oil droplets from the gel, and these oil droplets penetrate the stratum corneum of the skin and deliver the drug to the target area. Because the gel-based formula reduces the sticky effect on the skin, patient compliance is also improved compared to creams and ointments [21].

Besides being influenced by the dosage form, the penetration of drugs that cross the skin can also be increased by adding enhancers. To increase the transdermal permeation, penetration enhancers can alter the structure of the stratum corneum. For example, short-chain alkanols are widely used as permeation enhancers. It is known that oleic acid, a fatty acid with one double bond in the chain structure, disrupts the lipid barrier in the stratum corneum by forming separate domains that interfere with the multilamellar continuity of the stratum corneum and can lead to highly permeable pathways in the stratum corneum [22]. The use of oleic acid between concentrations of $1 \%$ and $10 \%$, with an optimal concentration of $5 \%$, when more than $5 \%$, will not give significant results.

The spread and penetration do not increase due to saturation due to the maximum drug solubility [23]. A high concentration of oleic acid can reduce the permeation rate caused by oil aggregation. In addition, the incorporation of oleic acid in the nanoemulgel could be one of the reasons for the increase in the cumulative percentage permeating through the stratum corneum [20]. Oleic acid has several mechanisms of action, firstly modifying the fat layer of the stratum corneum to form long-chain fatty acids with a cis configuration. Second, it creates a new lipid layer together with the stratum corneum lipid layer to reduce the capacity of the skin barrier function. Third, the nature of oleic acid is similar to the stratum corneum, so oleic acid is easier to penetrate the skin barrier. Fourth, separate the components of the stratum corneum membrane and increase the permeability to oleic acid. Fifth, lowering the temperature of the transition phase of the subcutaneous fat layer by increasing the fluidity of the skin and decreasing the diffusion resistance. Unsaturated fatty acids increase the diffusion coefficient significantly but have no significant effect on the partition coefficient of the stratum corneum [23].

Due to the various mechanisms of oleic acid, the penetration of both hydrophilic and lipophilic drugs such as caffeic acid, which is poorly soluble in water, can be increased by a suitable delivery system for solubility [24]. In addition, other advantages of this nanoemulgel formula show increased thixotropic flow, non-greasy, easy to spread, easy to remove, softness, soluble in water, longer shelf life, transparency, and pleasant appearance [25]. Research conducted by Žilius et al. (2013) determined the penetration of phenolic acids (coumaric acid, caffeic acid, and ferulic acid) in propolis from semisolid formulations (ointments, creams, and gels) using Franz diffusion cells, found that caffeic acid slowly penetrated the propolis. In the epidermis and not in the dermis, so that research has been carried out with the addition of oleic acid as a penetration enhancer and nanoemulgel technology, which is considered relevant for the development of semisolid systems so that the permeation of caffeic acid compounds in propolis into the skin is more efficient [10].

\section{Materials and Methods}

\section{Materials}

The ingredients used are propolis from Apis trigona was obtained from Forestry Faculty, Hasanuddin University, Indonesia, distilled water, oleic acid, caffeic acid were purchased from Sigma-Aldrich Pte Ltd., Singapore, gallic acid (Sigma-Aldrich®) Pte Ltd., Singapore, butylhydroxytoluene (BHT), carbopol 940, 70\% ethanol, methylparaben and propylparaben, $\mathrm{Na}_{2} \mathrm{CO}_{3} 7 \%$ (Emsure () ), propylene glycol, methanol (high-performance liquid chromatography [HPLC] grade, $99.9 \%$ ) was supplied by Merck, phosphate buffered saline (PBS) $\mathrm{pH} 7.4$, Folin-Ciocalteau reagent was purchased from Merck, triethanolamine (TEA), tween 80 was purchased from Merck and virgin coconut oil (VCO).

\section{Methods}

\section{Preparation and extraction of samples}

Propolis was extracted by maceration. Propolis samples were soaked in $70 \%$ ethanol for $3 \times 24 \mathrm{~h}$. Every $24 \mathrm{~h}$, the mixture was filtered and replaced with a new solvent. The filtering results were then concentrated 
with a rotary evaporator at $60^{\circ} \mathrm{C}$ then continued in a water bath at $50^{\circ} \mathrm{C}$ to obtain a thick extract.

\section{Determination of total phenolic content}

Modified determination of total phenolic content was used gallic acid equivalent (GAE) as standard [26], [27].

\section{Preparation of standard gallic acid curve}

A standard solution of $1000 \mu \mathrm{g} / \mathrm{ml}$ gallic acid was prepared by weighing $25 \mathrm{mg}$ of gallic acid dissolved in methanol pa to a volume of $25 \mathrm{ml}$. Afterward, the standard solution was pipetted $2.5,5,25,50$, and $125 \mu \mathrm{l}, 0.2 \mathrm{ml}$ of Folin-Ciocalteu reagent was added, shaken, and left for 4-8 min. In addition, $2.0 \mathrm{ml}$ of $7 \% \mathrm{Na}_{2} \mathrm{CO}_{3}$ solution was added, shaken until homogeneous. $5 \mathrm{ml}$ aqua bidestillata was added to produce concentrations of $0.5,1,5,10$, and $25 \mu \mathrm{g} / \mathrm{ml}$. The absorbance of gallic acid was measured at a maximum wavelength of $760 \mathrm{~nm}$. Next, the absorption of each concentration was measured at the maximum wavelength.

Quantitative determination of total phenolic compounds

Samples of propolis extract were weighed accurately $50 \mathrm{mg}$, dissolved in $70 \%$ ethanol to $50 \mathrm{ml}$. From the sample solution, $50 \mu \mathrm{l}$ was pipetted, and $0.2 \mathrm{ml}$ of Folin-Ciocalteu reagent was added, shaken, and allowed to stand for 4-8 $\mathrm{min}$, then $2.0 \mathrm{ml}$ of $7 \% \mathrm{Na}_{2} \mathrm{CO}_{3}$ solution was added, shaken until homogeneous. After that, $5 \mathrm{ml}$ aqua bidestillata was added to produce a concentration of $10 \mu \mathrm{g} / \mathrm{ml}$. Three series of replications were made with a concentration of $10 \mu \mathrm{g} / \mathrm{ml}$. The absorbance was measured at a maximum wavelength of $760 \mathrm{~nm}$, and a calibration curve was made for the relationship between gallic acid concentration $(\mu \mathrm{g} / \mathrm{ml})$ and absorbance. The average of the three readings was used, and the total phenolic content was expressed in mg GAE (mg/100 g).

Quantitative measurement of caffeic acid using the ultra-fast liquid chromatography (UFLC) method

Preparation of mobile phase

The mobile phase was a mixture of methanol: demineralized water $(10: 90 \mathrm{v} / \mathrm{v})$ to extract caffeic acid. The mobile phase contents were filtered before use through a $0.45 \mu \mathrm{m}$ membrane filter, sonicated, and pumped from the solvent reservoir to the column at a flow rate of $0.5 \mathrm{ml} / \mathrm{min}$. The samples were detected at $325 \mathrm{~nm}$. The column temperature was maintained at room temperature, and the injection volume was $20 \mu \mathrm{l}$. Before analyte injection, the column was equilibrated for 40-50 min with the mobile phase [28].
Calibration curve graph setup

Caffeic acid stock solution was prepared with a $1000 \mu \mathrm{g} / \mathrm{ml}$ concentration by dissolving $10 \mathrm{mg}$ of standard caffeic acid into $10 \mathrm{ml}$ of methanol grade HPLC. Then, from stock solution was pipetted 1, 5, 10, 20, 40, 60, 80, 100, and $160 \mu$ and PBS solution was added until $1 \mathrm{ml}$ into the UFLC vial to obtained $1,5,10,20,40,60,80,100$, and $160 \mu \mathrm{g} / \mathrm{ml}$. Then, it was injected for the preparation of the calibration curve graph. The calibration ratio on the chart was plotted using concentration versus peak area at $325 \mathrm{~nm}$ [29].

\section{Determination of caffeic acid levels in extracts}

The propolis extract was weighed $50 \mathrm{mg}$ diluted with $50 \mathrm{ml}$ of methanol to obtain a $1000 \mu \mathrm{g} / \mathrm{ml}$ concentration, then homogenized with a vortex and filtered through a $0.45 \mu \mathrm{m}$ membrane filter. The stock solution was pipetted $100 \mu \mathrm{l}$, and PBS solution was added until $1 \mathrm{ml}$ to obtain a $100 \mu \mathrm{g} / \mathrm{ml}$ concentration. Three series of dilutions were made for analysis.

\section{Fabrication of nanoemulgel propolis}

\section{extract}

\section{Preparation of gel base Carbopol 940}

Carbopol 940 was added with some amount of distilled water until completely dispersed and hydrated for $\pm 24 \mathrm{~h}$ and homogenized. Then TEA was mixed into the dispersion to form a clear gel. TEA was added as a $\mathrm{pH}$ neutralizer as well as a stabilizer for Carbopol 940. This mixture was homogenized at $1000 \mathrm{rpm}$ for \pm 5 minutes at room temperature.

\section{Nanoemulsion manufacturing}

The propolis extract-loaded nanoemulgel was prepared by a high-pressure homogenization method with slight modifications [30], [31]. The composition of the different formulations is given in Tables 1 and 2 . The oil phase was mixed at preparation glass, and propolis extract was dissolved with ethanol, VCO, BHT, and oleic acid was added then homogenized. Likewise, methylparaben

Table 1: Design Formula of Nanoemulgel

\begin{tabular}{lllll}
\hline Composition & \multicolumn{3}{l}{ Concentration b/b\% } & \\
\cline { 2 - 5 } & F1 & F2 & F3 & F4 \\
\hline Propolis ethanol extract & 2 & 2 & 2 & - \\
VCO & 5 & 5 & 5 & 5 \\
Oleic acid & 1.25 & 2.5 & 5 & 1.25 \\
Tween 80 & 25 & 25 & 25 & 25 \\
$70 \%$ alcohol & 5 & 5 & 5 & 5 \\
Methylparaben & 0.18 & 0.18 & 0.18 & 0.18 \\
Propylparaben & 0.02 & 0.02 & 0.02 & 0.02 \\
Propylene glycol & 5 & 5 & 5 & 5 \\
BHT & 0.1 & 0.1 & 0.1 & 0.1 \\
Aquadestilata ad & 100 & 100 & 100 & 100 \\
\hline BHT: Butylhydroxytoluene, VCO: Virgin coconut oil. & & &
\end{tabular}


and propylparaben were dissolved in propylene glycol, then tween 80 was added and stirred using a homogenizer at $1000 \mathrm{rpm}$ for $\pm 5 \mathrm{~min}$ until homogeneous as the aqueous phase. The oil phase was added to the water phase. The remaining water was added, then homogenized with a homogenizer at a speed of $10000 \mathrm{rpm}$ for $\pm 30 \mathrm{~min}$ at room temperature until homogeneous and a clear and transparent nanoemulsion was formed [30], [32].

Table 2: Formulation of gel bases

\begin{tabular}{ll}
\hline Composition & Concentration $\mathrm{b} / \mathrm{b} \%$ \\
\hline Carbopol 940 & 2 \\
TEA & 2 \\
Aquadestilata ad & 100 \\
\hline TEA: Triethanolamine. &
\end{tabular}

\section{Preparation of nanoemulgel}

The nanoemulsion and gel base preparations were mixed in a ratio of $1: 1$. It was then homogenized for \pm 5 min with a homogenizer at a speed of $1000 \mathrm{rpm}$ at room temperature to form a clear and transparent nanoemulgel.

\section{Determination of caffeic acid levels in nanoemulgel}

Preparations F1, F2, and F3 have weighed $50 \mathrm{mg}$ diluted with $50 \mathrm{ml}$ of PBS solution to obtain a $1000 \mu \mathrm{g} / \mathrm{ml}$ concentration, then filtered with a $0.45 \mu \mathrm{m}$ membrane filter. Take $1 \mathrm{ml}$ into a UFLC vial for injection. Three series of dilutions were made for analysis.

\section{Evaluation of physical properties of nanoemulgel preparations}

Evaluation of physical properties of nanoemulgel preparations includes:

\section{Physical characteristic test:}

Organoleptic test

Physical for all nanoemulgel samples was observed every week for 4 weeks. Color, odor, and visual texture changes are the observed parameters [32], [33].

$\mathrm{pH}$ test

The $\mathrm{pH}$ test was carried out using a $\mathrm{pH}$ meter Handylab pH Schott Instrument, which was calibrated first using a basic solution of $\mathrm{pH} 10$. Measurement was carried out by dipping the indicator into the preparation. Then record the results obtained [34].

\section{Viscosity test}

This measurement was carried out with three repetitions using a Brookfield DV-E viscometer. The sample's viscosity was measured using the Brookfield viscosity with spindle number 5 , and the spindle was run at a speed of $50 \mathrm{rpm}$. The consistency of nanoemulgel is calculated by multiplying the number recorded on the dial reading by the number listed in the conversion factor table [35]. Record and convert the viscosity measurement results with the formula:

$$
\text { Viscosity }=\% \mathrm{~T} x f
$$

$\% \mathrm{~T}=$ percent torque/Dial reading

$f=$ conversion factor

Particle size determination test and polydispersity index (Pdl)

Nanoemulsion Gel Droplet size and Pdl tests were carried out using a Size Analyzer with Dynamic Light Scattering type made in triplicate using Zetasizer (ZS90; Malvern Instruments Ltd., Malvern, UK). Each sample $(100 \mathrm{~L})$ was diluted with distilled water in a ratio of 1:100 before being analyzed [36].

\section{Zeta potential assay}

The zeta potential $(\zeta)$ of propolis extract NE system optimized via laser Doppler anemometry using Zetasizer (ZS90; Malvern Instruments Ltd., Malvern, UK). Each sample (100 L) was diluted with distilled water in a ratio of 1:100 before being analyzed [36].

\section{Spreadability test}

A total of $1 \mathrm{~g}$ of the preparation was placed in the center of a round glass scale. On top of the practice was placed another round glass and ballast so that the round glass and $125 \mathrm{~g}$ weight were left for $1 \mathrm{~min}$, then the distribution was recorded. This test was carried out once, that is, $48 \mathrm{~h}$ after the preparation has been made [33], [37].

\section{Adhesion test}

A total of $0.25 \mathrm{~g}$ of the preparation was placed on a glass object whose area has been determined. Then another glass object was placed on top. Then, the glass object was mounted on the test equipment and given a load of $1 \mathrm{~kg}$ for $5 \mathrm{~min}$ then released with a pack weighing $80 \mathrm{~g}$. The time was recorded until the two object glasses were removed [38].

\section{Nanoemulgel physical stability test:}

Centrifugation test

The preparation was put into a centrifugation tube and then centrifuged at a speed of $5000 \mathrm{rpm}$ for $30 \mathrm{~min}$. Observation of phase separation was carried out at each time interval until separation occurred [39]. 
Freeze-thaw test

The freeze-thaw method is carried out by storing the preparation at a temperature of $-20^{\circ} \mathrm{C}$ and $25^{\circ} \mathrm{C}$ for no more than $48 \mathrm{~h}$ ( 1 cycle). Parameters measured for stability were $\mathrm{pH}$ and viscosity for all nanoemulgel formulas. The fundamental steps were repeated for three cycles [39].

\section{Heating stability test}

The stability test was carried out using an oven stability test using a temperature of $60-100^{\circ} \mathrm{C}$. Samples were stored for $5 \mathrm{~h}$, and after completion of the test, physical characteristics were observed, including organoleptic observations [39].

\section{Permeation and retention ex vivo test:}

\section{Preparation of $\mathrm{PBS} \mathrm{pH} 7.4$}

$\mathrm{NaCl} 8 \mathrm{~g}, \mathrm{Na}_{2} \mathrm{HPO} 42.38 \mathrm{~g}$, and $\mathrm{KH}_{2} \mathrm{PO}_{4} 0.19 \mathrm{~g}$ were weighed and put into a $1000 \mathrm{ml}$ volumetric flask, then diluted with $\mathrm{CO} 2$-free water to $\pm 800 \mathrm{ml}$. The degree of acidity of the solution was measured by a $\mathrm{pH}$ meter until it reaches a $\mathrm{pH}$ of 7.4 , and water $\mathrm{CO} 2$-free was added to $1 \mathrm{I}$ [40].

\section{Permeation test}

The modified Franz diffusion cell was used to study drug permeation from the reservoir through nanoemulgel preparations on rat skin. The diffusion test was carried out using a Franz diffusion cell. The liquid receptor compartment on the device was filled with PBS $\mathrm{pH} 7.4$, which has been heated to $\pm 37^{\circ} \mathrm{C}$ to total $(28 \mathrm{ml})$, the stirrer was inserted into the Franz diffusion cell. The nanoemulgel preparation was placed on the skin of mice in a Franz diffusion cell. After that, it was closed with a glass lid and equipped with a rubber clamp, then placed on a magnetic stirrer whose temperature and speed had been regulated. The magnetic stirrer was turned on, and the rotation scale is adjusted; the temperature was maintained at $\pm 37^{\circ} \mathrm{C}$. Sampling $(1 \mathrm{ml})$ was carried out successively at 15, 30, 60, 120, 240, 360, 480, and $1440 \mathrm{~min}$. Each sample taken was replaced with PBS $\mathrm{pH} 7.4$ with the same volume and temperature. Determination of the levels of the sample was done by UFLC. Permeation studies were performed in triplicates [41]. The caffeic acid permeation parameter of nanoemulgel was calculated by plotting the amount of drug absorbed through the rat skin membrane $\left(\mu \mathrm{g} / \mathrm{cm}^{2}\right)$ versus time (second). The steady-state flux value $(\mathrm{J})$ of all nanoemulgel formulas was evaluated from the linear increase of the permeation graph through the equation:

$$
\mathrm{J}\left(\mu \mathrm{g} /\left(\mathrm{cm}^{2} \mathrm{~s}\right)\right)=\frac{d Q}{A d t}
$$

where $Q$ represents the amount of substance that crosses the rat skin membrane, $A$ is the area of the exposed rat skin membrane, and $t$ is the exposure time. The permeation coefficient $(P)$ in each formula is calculated from the following equation:

$$
P\left(\mathrm{~cm}^{2} / \mathrm{s}\right)=\frac{J}{\mathrm{CO}}
$$

where $C_{0}$ represents the initial drug concentration in the donor compartment [42].

\section{Retention test}

After the permease test, the rat skin was cut into small pieces and extracted with ethanol in a sonicator bath for $2 \mathrm{~h}$. The supernatant was taken and centrifuged for $15 \mathrm{~min}$ at $5000 \mathrm{rpm}$. The supernatant was collected, and UFLC was performed for analysis [43].

\section{Drug release kinetics}

Data obtained from permeation studies were fitted to different kinetic models (Zero-order, First-order, and Higuchi) to determine the mechanism of caffeic acid release from nanoemulgel with the following formula:

$$
\begin{aligned}
& \text { Zero-order: } \mathrm{A}_{\mathrm{t}}=\mathrm{A}_{0}+K_{0} t \\
& \text { First-order: } \ln \mathrm{A}_{\mathrm{t}}=\ln \mathrm{A}_{0}+K_{1} t \\
& \text { Higuchi: } \mathrm{A}_{\mathrm{t}}=\mathrm{K}_{\mathrm{H}} \sqrt{t}
\end{aligned}
$$

where $A_{t}$ is the percentage of drug released at time $t, A_{0}$ is the initial value of $A_{t} t$ is the time, $K_{0}, K_{1}$ $\mathrm{K}_{\mathrm{H}}$ are the release coefficients following the relevant kinetic models [33], [44].

\section{Data analysis}

Analysis the data presented are expressed as mean \pm standard deviation (SD) from the mean. Calculations were performed using Microsoft ${ }^{\circledR}$ Excel $\AA$ in 2016 (Microsoft Corporation, Redmond, USA). Statistical analysis was performed using GraphPad Prism $®$ version 6 (GraphPad Software, San Diego, California, USA).

\section{Results and Discussion}

\section{Determination of total phenolic content}

From the measurement results, the total phenolic content of the propolis ethanol extract was $112.29 \pm 5.19 \mathrm{mg} / \mathrm{g}$, calculated equivalent to $\mathrm{mg}$ GAE to grams of propolis extract GAE. The phenolic content of propolis ranges between $65.49 \mathrm{mg} \mathrm{GAE} / \mathrm{g}$ 
and $228.40 \mathrm{mg} \mathrm{GAE} / \mathrm{g}$ [45]. Several previous studies of propolis found a total phenolic content of 152.29 $\pm 3.82 \mathrm{mg} \mathrm{GAE} / \mathrm{g}$ [46] and $179.32 \pm 9.32 \mathrm{mg} \mathrm{GAE} / \mathrm{g}$ extract [43]. In several countries such as China, Lithuania, Brazil, Turkey, and Portugal, it has been reported to have total phenolic between 29.5 and $329 \mathrm{mg} \mathrm{GAE} / \mathrm{g}$ with the gallic acid standard [46], [48], [49], [50]. Research by Lagouri et al. (2014) suggests several things that affect the difference in total phenolic such as extraction method, solvent, and geographical location. From the solvent used $80 \%$ methanol, methanol, and water between the western Macedonia and Rhodes regions, the highest yield was of west Macedonia with $80 \%$ methanol solvent of $179.99 \pm 3.43 \mathrm{mg} \mathrm{GAE} / \mathrm{g}$, and the lowest was from the Rhodes area with water solvent of 2.33 $\pm 0.51 \mathrm{mg} \mathrm{GAE} / \mathrm{g}$. In Indonesia, several studies have also been conducted from SEAFAST Indonesia on bee propolis in some areas. The results showed that the total phenolic content ranged between $39.9 \pm$ $54 \mathrm{mg}$ and $376.3 \pm 18.8 \mathrm{mg} \mathrm{GAE} / \mathrm{g}$ extract [51]. The total phenolic concentration test was carried out using gallic acid as a standard for comparison with FolinCiocalteu ( $\mathrm{F}-\mathrm{C})$ reagents and $\mathrm{Na}_{2} \mathrm{CO}_{3}$, then measured by ultraviolet-visible (UV-Vis) spectrophotometer. $\mathrm{F}-\mathrm{C}$ reacts with phenolic compounds to produce a blue color. The blue color in the solution is due to the molybdenum metal (Mo[VI]) in the reagent complex being reduced to $\mathrm{Mo}(\mathrm{V})$ in the presence of electron donors by antioxidants which can be measured using a spectrophotometer at a wavelength of $760 \mathrm{~nm}$ [52]. $\mathrm{Na}_{2} \mathrm{CO}_{3}$ serves to provide an alkaline atmosphere; the reaction occurs if the $\mathrm{pH}$ is $\sim 10$; under these conditions, F-C will be easily reduced by the dissociation of phenolic protons leading to the formation of phenolic ions [53].

\section{Determination of caffeic acid levels in extracts}

Determination of caffeic acid content was analyzed by the UFLC method. UFLC chromatogram of standard caffeic acid and propolis ethanol extract with a retention time of 3.4 min is shown in Figure 1. The measurement results obtained that the levels of caffeic acid in propolis extract were $6.037 \pm 1.27 \mathrm{mg} / \mathrm{g}$ extract. The previous research by Lagouri et al. (2014) of $0.64 \pm 0.01 \mathrm{mg} / \mathrm{g}-4.17 \pm 0.27 \mathrm{mg} / \mathrm{g}$ of caffeic acid extract with methanol as a solvent. In contrast to the results obtained by Balata et al. (2018), research with caffeic acid levels of $29.04 \pm 1.56 \mathrm{mg} / \mathrm{g}$. The findings of other studies in other geographic areas with phenolic acids include caffeic acid (3.3-32.2 mg/g) [54]. The results obtained are relatively low because the phenolic compounds besides caffeic acid consist of coumaric acid, ferulic acid, Caffeic acid phenethyl ester, vanillic acid, and others [47].

\section{Evaluation of physical properties of nanoemulgel preparations}

Determination of caffeic acid concentration in nanoemulgel preparations

Determination of the levels of caffeic acid in the preparations $\mathrm{F} 1, \mathrm{~F} 2$, and $\mathrm{F} 3$ nanoemulgel propolis extract was intended to determine how many mg levels of dissolved caffeic acid were in these preparations. The weight of caffeic acid obtained in the preparation determines how many mg of caffeic acid are in each gram of the nanoemulgel preparation. The average caffeic acid content obtained for each formula F1, F2, and F3 was $0.1151 \pm 0.0060 \mathrm{mg} / \mathrm{g}$; $0.1099 \pm 0.0114 \mathrm{mg} / \mathrm{g}$; and $0.1128 \pm 0.0071 \mathrm{mg} / \mathrm{g}$ of the nanoemulgel preparation. F4 as a control does not contain caffeic acid. The concentration of $2 \%$ extract is equivalent to $2 \mathrm{~g}$ of extract in $100 \mathrm{~g}$ of preparation so that $1 \mathrm{~g}$ of the preparation contains $20 \mathrm{mg}$ of extract.

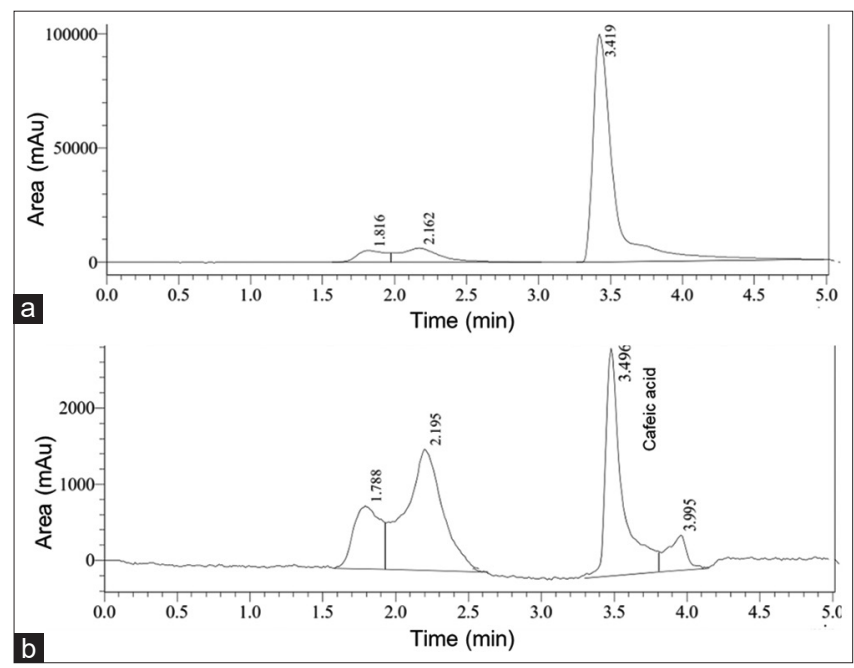

Figure 1: The ultra-fast liquid chromatography chromatograms of standard Caffeic acid (a) and ethanol extract of propolis (b)

\section{Physical characteristics test}

Organoleptic test

Nanoemulgel formulations of F1, F2, and F3 were semisolid with a homogeneous texture, brown color, and a characteristic odor of oil at the beginning of their formation and after storage for 4 weeks at room temperature of $27^{\circ} \mathrm{C}$, while nanoemulgel $\mathrm{F} 4$ was a semisolid with a homogeneous texture, white color, and characteristic odor oil. Photos of the observations of the organoleptic nanoemulgel formulas F1, F2, F3, and F4 at the time of the first formation and after storage for 4 weeks at room

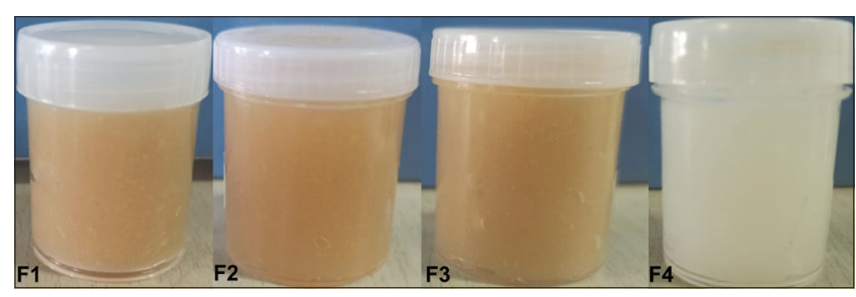

Figure 2: Nanoemulgel preparations propolis extract 
Table 3: Results of organoleptic observations nanoemulgel preparations propolis extract

\begin{tabular}{|c|c|c|c|c|c|}
\hline \multirow[t]{2}{*}{ Formula } & \multirow[t]{2}{*}{ Observation } & \multicolumn{4}{|c|}{ Observation time (week of-) } \\
\hline & & 1 & 2 & 3 & 4 \\
\hline \multirow[t]{2}{*}{ F1 } & $\begin{array}{l}\text { Color } \\
\text { Odor }\end{array}$ & $\begin{array}{l}\text { Brown } \\
\text { distinctive odor }\end{array}$ & $\begin{array}{l}\text { Brown } \\
\text { distinctive odor }\end{array}$ & $\begin{array}{l}\text { Brown } \\
\text { distinctive odor }\end{array}$ & $\begin{array}{l}\text { Brown } \\
\text { distinctive odor }\end{array}$ \\
\hline & Consistency & Homogeneous & Homogeneous & Homogeneous & Homogeneous \\
\hline \multirow[t]{2}{*}{$\mathrm{F} 2$} & $\begin{array}{l}\text { Color } \\
\text { Odor }\end{array}$ & $\begin{array}{l}\text { Brown } \\
\text { distinctive odor }\end{array}$ & $\begin{array}{l}\text { Brown } \\
\text { distinctive odor }\end{array}$ & $\begin{array}{l}\text { Brown } \\
\text { distinctive odor }\end{array}$ & $\begin{array}{l}\text { Brown } \\
\text { distinctive odor }\end{array}$ \\
\hline & Consistency & Homogeneous & Homogeneous & Homogeneous & Homogeneous \\
\hline \multirow[t]{2}{*}{ F3 } & Color & Brown & Brown & Brown & Brown \\
\hline & Consistency & Homogeneous & Homogeneous & Homogeneous & Homogeneous \\
\hline \multirow[t]{3}{*}{ F4 } & Color & white & white & white & white \\
\hline & Odor & distinctive odor & distinctive odor & distinctive odor & distinctive odor \\
\hline & Consistency & homogeneous & homogeneous & homogeneous & homogeneous \\
\hline
\end{tabular}
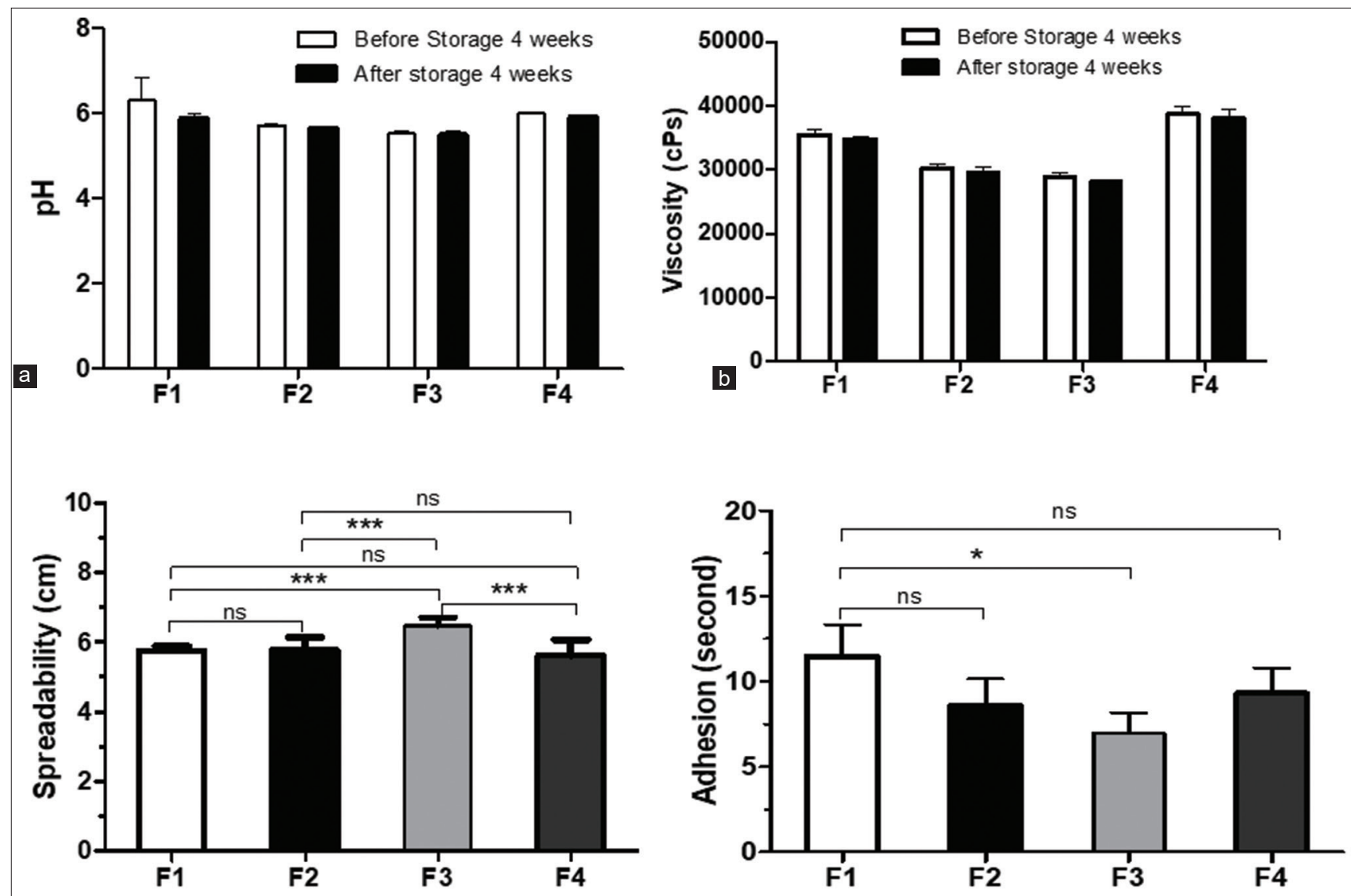

c

d
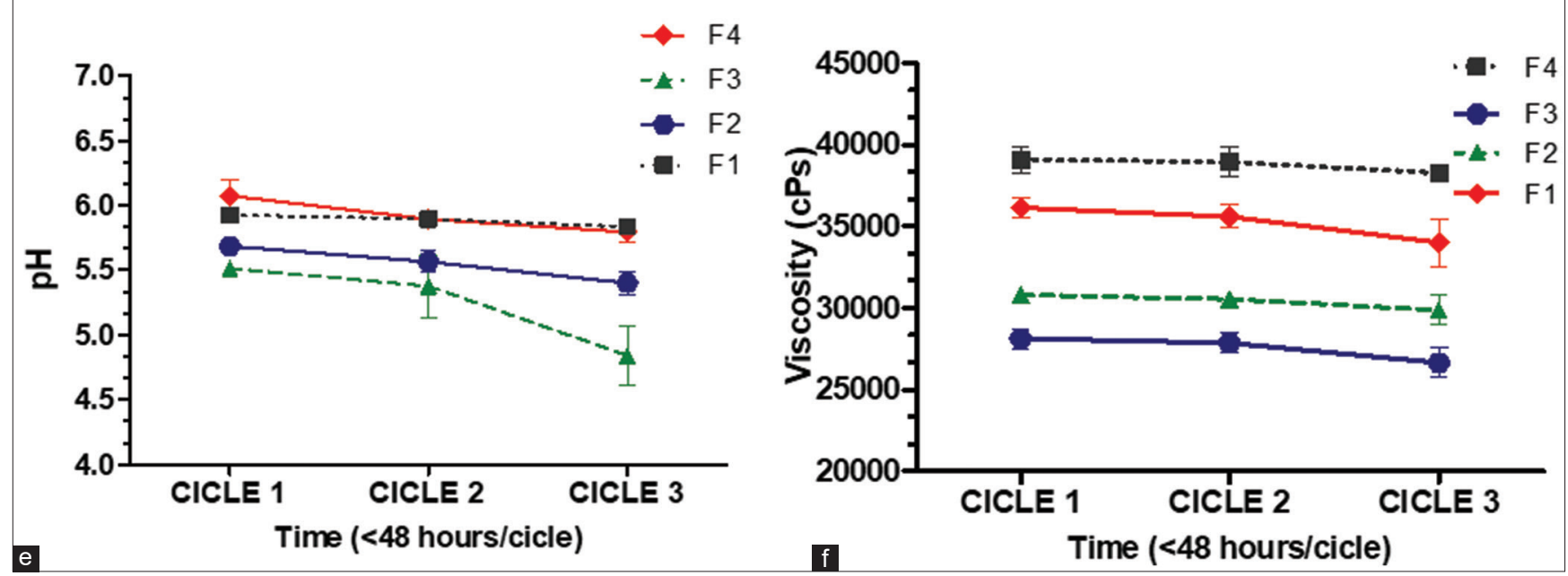

Figure 3: The results of measuring the $\mathrm{pH}$ of nanoemulgel before and after storage for 4 weeks (a), measuring the viscosity of nanoemulgel before and after storage for 4 weeks (b), dispersion (c), adhesion (d), Freezee thaw pH test (e), frezee thaw viscosity test (f), F1 = Nanoemulgel with $1.25 \%$ oleic acid concentration, $F 2=$ Nanoemulgel with $2.5 \%$ oleic acid concentration, F3 = Nanoemulgel with $5 \%$ oleic acid concentration F4 = Nanoemulgel without propolis extract, $\left(^{*}{ }^{* * *}\right)=$ Significant $(p<0.05)$. Ns $=$ Not Significant $(p<0.05)$ 
temperature $27^{\circ} \mathrm{C}$ are shown in Figure 2 and Table 3. These observations prove that during storage for 4 weeks, the organoleptic nanoemulgel did not experience changes.

$\mathrm{pH}$ test

The results of the measurement of the $\mathrm{pH}$ of nanoemulgel formula F1 before 4 weeks of storage for formulas F1, F2, F3, and F4 had a pH of $6.0 \pm 0.20 ; 5.71$ \pm 0.03 ; $5.52 \pm 0.05$; and $5.99 \pm 0.03$ and after storage for 4 weeks at $27^{\circ} \mathrm{C}$ for the formulas F1, F2, F3, and F4 had a $\mathrm{pH}$ of $5.94 \pm 0.03 ; 5.64 \pm 0.01 ; 5.49 \pm 0.09$; and $5.91 \pm$ 0.03 . The two-way analysis of variance (ANOVA) statistical analysis results on the F1, F2, F3, and F4 formulas before and after 4 weeks of storage with $p>0.05$ indicated that the decrease was not significant. During 4 weeks of storage, there was a decrease as shown in the histogram, but the $\mathrm{pH}$ value was in the normal skin $\mathrm{pH}$ range of 4.56.5 , which was acceptable and non-irritating for use on human skin [32], [55]. The histogram of $\mathrm{pH}$ values in the four formulas is shown in Figure 3.

\section{Viscosity test}

The results of measuring the viscosity of nanoemulgel at $50 \mathrm{rpm}$ with spindle number 5 for formulas F1, F2, F3, and F4 before and after 4 weeks of storage are shown in Table 4. The viscosity of nanomulgel propolis extract with p-value 0.2552 $(p>0.05)$, which indicated that there was no significant difference. Based on these results, it can be seen that the F3 formula has the lowest viscosity compared to the F1, F2, and F4 formulas. These results indicate that the higher the concentration of oleic acid used, the lower the viscosity value produced. It happens because the increase in oleic acid affects the consistency; the preparation becomes runnier; this is due to the more effective the oleic acid content used in the formulation, the greater the HLB needed and the surfactant level required to form micelles so that the required tween 80 content is also more significant. The content of the inner phase, namely large oleic acid, also makes the emulsion more unstable because of the greater interfacial tension, thus requiring more tween 80 [56]. The results of testing the viscosity of the preparations on the formulas F1, F2, F3, and F4 meet the requirements for suitable density of semisolid preparations ranging from 4.000 to $40.000 \mathrm{cP}$ [57], [58]. Tables and histograms of $\mathrm{pH}$ values in the four formulas are shown in Table 4 and Figure 3.

\section{Determination of particle size, $\mathrm{Pdl}$, and zeta potential}

The results of the measurement of nanoemulgel particles F1 when they were initially formed had an average particle size of $213.47 \pm 18 \mathrm{~nm}, \mathrm{~F} 2$ had an average particle size of $204.23 \pm 11.61 \mathrm{~nm}, \mathrm{~F} 3$ had a particle size of 137.28 $\pm 1.11 \mathrm{~nm}$, and F4 had a particle size of $137.28 \pm 1.11 \mathrm{~nm}$. Particle size was $272.29 \pm 0.50 \mathrm{~nm}$.

Based on the one-way ANOVA statistical test results, the results of a significance value of 0.0001 $(p<0.05)$ can be seen as a significant difference between the droplet sizes of the four formulas. Then continued with the post hoc t-test of the Tukey's test method from the comparison of the four formulas, there was no significant difference between the F1 and F2 formulas. However, there are substantial differences between the formulas F1 and F3, F1 and F4, F2 and $\mathrm{F} 3, \mathrm{~F} 2$ and F4, and F3 and F4. The particle size of the nanoemulsion preparation of the propolis extract gel produced a size range of 100-300 nm. Nanoemulsion preparations have an average particle size of about 20-500 nm [59], [60]. The resulting particle size range has met the requirements.

In addition to droplet size, the Pdl value helps provide information about the stability and uniformity of nanoemulsion droplet size. The particle size distribution is expressed as mono dispersion if the $\mathrm{Pdl}$ is between 0.01 and 0.7 [61]. Range The Pdl value in the preparation of nanoemulsion gel extract of propolis in each formula shows a value below 0.5 which was still acceptable because the droplet size distribution was uniform and homogeneous (Table 5). The statistical analysis of the Pdl showed a significance value of 0.0002 ( $p<0.05)$. It could be seen that there was a significant difference between the Pdl of the four formulas. Then continued with the post hoc t-test Tukey's Test method from the comparison of the four formulas F1 and F4, F2 and F3 each with a significance value $(p>0.05)$ which indicates there was no significant difference for these formulas with the same oleic acid concentration, namely, F1 and $\mathrm{F} 4$ by $1.25 \%$. Then there is a considerable difference between the formulas F1 and F2 and F2 and F4. The value of the $\mathrm{Pdl}$ in the nanoemulsion indicates the quality of the homogeneity or stability of particle size. The smaller the PI value, close to 0 , shows a more uniform and homogeneous droplet size [38]. In addition, a Pdl value below one is considered ideal for topical delivery because it will provide a large surface area, resulting in rapid pore transport [30]. Details of the Pdl are shown in Table 5 and Figure 4.

Table 4: Measurement results of $\mathrm{pH}$ and viscosity of nanoemulgel before and after 4 weeks of storage $(\operatorname{mean} \pm S D, n=3)$

\begin{tabular}{llll}
\hline Formula & Average of $\mathrm{pH} \pm \mathrm{SD}$ & & Average of Viscosity \pm SD (cPs) \\
\cline { 2 - 3 } & Before storage 4 weeks & After storage 4 weeks & \\
\hline F1 & $6.29 \pm 0.54$ & $5.87 \pm 0.10$ & $35466.7 \pm 923.8$ \\
F2 & $5.71 \pm 0.03$ & $5.64 \pm 0.01$ & $30266.7 \pm 611.0$ \\
F3 & $5.52 \pm 0.05$ & $5.49 \pm 0.09$ & $28800.0 \pm 692.8$ \\
F4 & $5.99 \pm 0.03$ & $5.91 \pm 0.03$ & $38666.7 \pm 1222.0$ \\
\hline
\end{tabular}




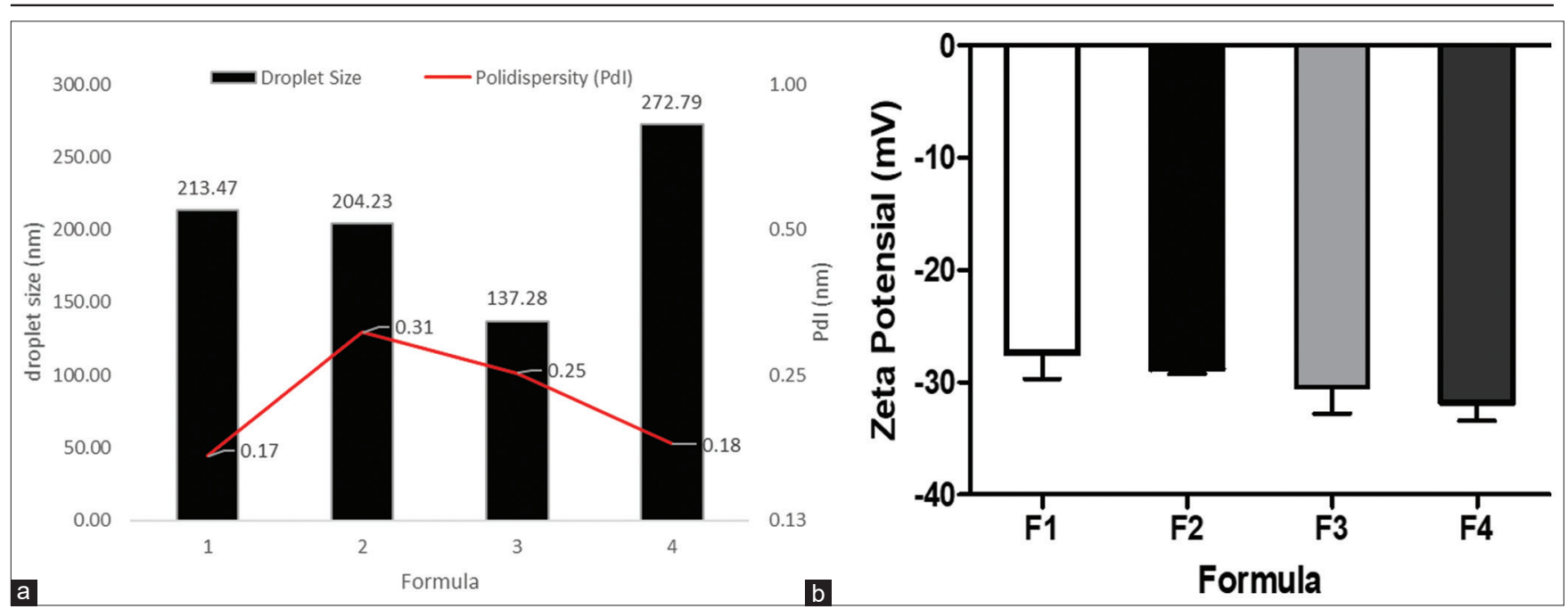

Figure 4: Histogram of particle size, polydispersity index (a), dan zeta potential (b)

Based on the statistical analysis of the t-test method, the two-tail $P(T<=t)$ value $\leq 0.0001$ Smaller than $p$-value $=0.05$ (level of significant $5 \%$ $0.0001<0.05$ ) indicating that the data are significantly different. It shows that the variation in the concentration of oleic acid statistically has a significant effect on the particle size of each formula. The t-test method used is the t-test type 3 method (unequal variance assumed), where the data being compared is two sample data with the assumption of unequal variations. For type 1 , two samples for facilities/tools with the same number of variables, and type 2 for two samples assuming the same variation. Two-tail is used because the data analyzed are unstable or free to experience a decrease or increase (two-way testing). While the one-tail is used for stable data, it does not significantly differ whether it increases or decreases (one-way test).

Table 5: Result of particle size, Pdl, and zeta potential (mean $\pm \mathrm{SD}, \mathrm{n}=3$ )

\begin{tabular}{llll}
\hline Formula & Particle size $(\mathrm{nm})$ & Pdl $(\mathrm{nm})$ & Zeta Potential $(\mathrm{mV})$ \\
\hline F1 & $213.47 \pm 1.80$ & $0.17 \pm 0.03$ & $-27.40 \pm 2.27$ \\
F2 & $204.23 \pm 11.61$ & $0.31 \pm 0.02$ & $-28.78 \pm 0.48$ \\
F3 & $137.28 \pm 1.11$ & $0.25 \pm 0.01$ & $-30.46 \pm 2.34$ \\
F4 & $272.79 \pm 0.58$ & $0.18 \pm 0.01$ & $-31.81 \pm 1.60$ \\
\hline \multicolumn{2}{l}{ Pdl: Polydispersity index. }
\end{tabular}

The mean zeta potential values of the formulas $\mathrm{F} 1, \mathrm{~F} 2, \mathrm{~F} 3$, and F4, respectively $-27.4 \pm 2.27 \mathrm{mV},-28.78$ $\pm 0.48 \mathrm{mV},-30.46 \pm 2.34 \mathrm{mV}$, and $-31.81 \pm 1.60 \mathrm{mV}$, were considered ideal for preventing coalescence and maintains the interfacial boundary of the nanoemulsion droplets resulting in better stability of the colloidal system. According to Mao's et al. nanoemulsion research (2019), against zeta potential was obtained $-29.10 \pm 1.27 \mathrm{mV}$, which indicated that the nanoemulsion was stable [62]. Statistical analysis using the One Way ANOVA test on the four nanoemulgel formulas showed no significant difference in each formula $(p>0.05)$. It shows that the variation of oleic acid concentration statistically does not significantly affect the zeta potential of each formula. The zeta potential is defined as the potential difference between the surface of the tightly bound layer and the electroneutral region of the system. Zeta potential is measured as a parameter in determining the surface charge of colloidal particles and the level of stability of a nanoemulsion and measuring the charge on the surface of droplets dispersed in a nanoemulsion system [36]. Nanoemulsions with a higher zeta potential value have a high degree of stability than a low zeta potential value and will flocculate faster. A stable colloidal nanoemulsion must have a zeta potential value of more than $-30 \mathrm{mV}$ and $+30 \mathrm{mV}$ [63]. In contrast, preparations with a small zeta potential value show fast particle aggregation due to Van der Waals forces [64]. The full zeta potential of the nanoemulsion gel extract of propolis extract is shown in Table 5 and Figure 4.

\section{Spreadability test}

Formulas F1, F2, and F4 have almost the same dispersion, namely $5.75 \pm 0.12,5.77 \pm 0.37$, and 5.72 \pm 0.38 . Only formula F3 has a high distribution of 6.47 \pm 0.24 . ANOVA showed a significant difference in the dispersion in each formula of $0.0001(p<0.05)$. The post-hoc test uses Tukey's test method among the four formulas. The results show that the formula F3 was significantly different compared to formulas F1, F2, and $\mathrm{F} 4$, then obtained that there was no significant difference between formulas F1 and F2, F1 and F4, and F2 and $\mathrm{F} 4$. The higher the spreadability of nanoemulgel with F3 concentration of $5 \%$ oleic acid. Based on the results of the dispersion test of the nanoemulgel preparations, it can be concluded that the nanoemulgel formulations of formulas F1, F2, F3, and F4 have met the dispersibility requirements. The dispersion requirement for topical preparations should be about $5-7 \mathrm{~cm}$. The dispersion test on nanoemulgel was carried out to determine the ability of the preparation to spread on the skin, which indicates the ease of use of the preparation on the skin. Good dispersion when it is easily spread on the skin, without applying tremendous pressure. Good dispersion causes the contact between the drug and the skin to be wide so that the absorption of the drug into the skin takes 
place quickly. The dispersion ability is influenced by the components that make up the material; the more liquid components, the larger the spread diameter, and vice versa, where a semisolid preparation should have good dispersion to ensure good drug delivery [57], [65], [66].

\section{Adhesion test}

The results of the adhesion test are presented in Figure 3, ranging from 6 to $12 \mathrm{~s}$. The results of this adhesion test were then analyzed using ANOVA with a $95 \%$ confidence level. The statistical tests showed a significant difference in the adhesion test data of 0.043 $(p<0.05)$. Afterward, a post hoc test was carried out using Tukey's test method to see the difference between the nanoemulgel formulas. The test results showed that there was a significant difference between the formulas $\mathrm{F} 1$ and $\mathrm{F3}$, with differences in the concentration of oleic acid between $1.25 \%$ and $5 \%$, while the comparison of the other formulas was F1 and F2, F1 and F4, F2 and F3, F2 and F4, and F3 and F4 there was no significant difference $(p>0.05)$. Thus, it can be concluded that the concentration of oleic acid affects the adhesion to the skin.

The adhesion test on nanoemulgel was carried out to see the ability to adhere to the skin, which could affect the penetration ability of nanoemulgel into the skin to cause an effect. The adhesion test results showed that the increase in the concentration of oleic acid with the tween that remained in the nanoemulgel preparation decreased the adhesion ability of the preparation. The low viscosity influenced this because the increase in oleic acid as one of the oil phase ingredients was not followed by an increase in tween as the water phase so that the required HLB point was not found. The adhesive power allows for a longer contact time of the preparation with the skin so that the penetration of nanoemlugel can produce a better effect. It shows that nanoemulgel preparations with various concentrations of oleic acid meet the requirements for adhesion. The need for adhesion to topical preparations is not <4 s [57], [65], [66].

\section{Physical stability test of nanoemulgel}

\section{Centrifugation test}

Thecentrifugationtestwascarried outtodetermine the effect of gravity on the stability of nanoemulgel, which is equivalent to the force of gravity for 1 year [55], [67]. From the observations of the centrifugation test at a speed of $4.000 \mathrm{rpm}$ for $30 \mathrm{~min}$, it was found that the four nanoemulgel formulas remained stable, and there was no phase separation after centrifugation. The results of these observations can be seen in Figure 4, nanoemulgel before centrifugation ( $A$ ) and after centrifugation. These results indicate that the four formulas are stable against the influence of gravity for 1 year.

\section{Freeze-Thaw test}

In this study, a freeze-thaw test was carried out to show the stability of the nanoemulgel preparation in the sample experiencing two varying extreme temperature changes. The results of the freeze-thaw test observation at a temperature of $-20^{\circ} \mathrm{C}$ for $48 \mathrm{~h}$ followed by a temperature of $25^{\circ} \mathrm{C}$ for $48 \mathrm{~h}$ (counting one cycle) and carried out for three cycles. It can be seen that the four nanoemulgel formulas remained stable because no phase separation occurred when the initial formation of nanoemulgel was until the $3^{\text {rd }}$ cycle. After the organoleptic test, $\mathrm{pH}$ and viscosity tests were carried out. The results of the freeze-thaw test observation are shown in Figure 5. Test the results of ANOVA statistical analysis on the comparison of $\mathrm{pH}$ test values $p=0.0001(p<0.05)$ showed a significant difference between cycles 1,2 , and 3 . From the post hoc test follow-up analysis from cycle 1 to cycle 2, there was no significant difference for the formulas $F 1$ and F4 ( $p>0.05$ ). In F2 and F3, there was a considerable difference with the $p$-value, $p<0.05$ and $p<0.01$, respectively. From cycle 2 to cycle 3 , the formulas $F 1, F 2$, and F4 with a $p>0.05$ showed no significant difference for each formula. Inversely proportional to the F3 formula, which experienced a substantial change with $p<0.001$. The analysis of the viscosity test with ANOVA showed a significant difference with a $p<0.0001$. They were followed by post hoc test analysis to see the significance of each formula with a comparison between cycles 1,2 , and 3 . The average change in formulas F1, F2, and F3 viscosity decreased with a $p<0.001$, indicating a significant difference. For the F4 formula with a $p>0.05$ for all cycles, it suggests that there was an insignificant change.

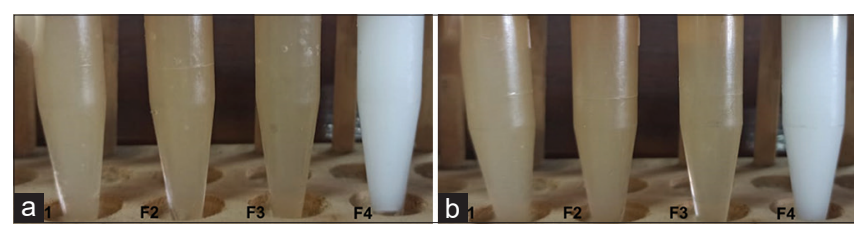

Figure 5: Test results centrifugation, before centrifugation (a), after centrifugation (b)

\section{Heating stability test}

The observations of heating stability tests at temperatures of $60^{\circ} \mathrm{C}, 70^{\circ} \mathrm{C}, 80^{\circ} \mathrm{C}, 90^{\circ} \mathrm{C}$, and $100^{\circ} \mathrm{C}$ for $5 \mathrm{~h}$, showed that the formulas F1, F2, F3, and F4 underwent organoleptic changes starting at $90^{\circ} \mathrm{C}$. The results obtained are due to nonionic surfactants, especially those with polyoxyethylene groups such as Tween 80 . Tween 80 is sensitive to temperature, so that it will affect the thermodynamic stability of the system. As the temperature increases, nonionic surfactants will become more lipophilic. The polyoxyethylene group that functions as a polar or head group will dehydrate with increasing temperature resulting in increased interfacial tension between oil and water so that the appearance 
of the nanoemulgel becomes unstable. Oleic acid is also not resistant at high temperatures between $80^{\circ} \mathrm{C}$ and $100^{\circ} \mathrm{C}$ because it will decompose [68].

\section{Permeation test}

Determination of the permeated caffeic acid content was carried out using UFLC analysis. In UFLC analysis, the maximum wavelength of caffeic acid was $325 \mathrm{~nm}$. Next, a standard curve was made that shows the excellent linearity produced by the standard curve of caffeic acid. Therefore, the resulting standard curve can be used as a reference in determining the levels of caffeic acid. The graph in Figure $6 a$ showed the percentage of permeated nanoemulgel propolis extract. On the F1 chart, F2 begins to permeate at the $7^{\text {th }} \mathrm{h}$ with an average percent permeation of $0.02 \%$ and $0.22 \%$, and $\mathrm{F} 3$ was permeated at the $6^{\text {th }} \mathrm{h}$ with a permeation of $0.08 \%$ while, F4 the amount of permeation was $0 \%$ as control of physical stability without extract ingredients

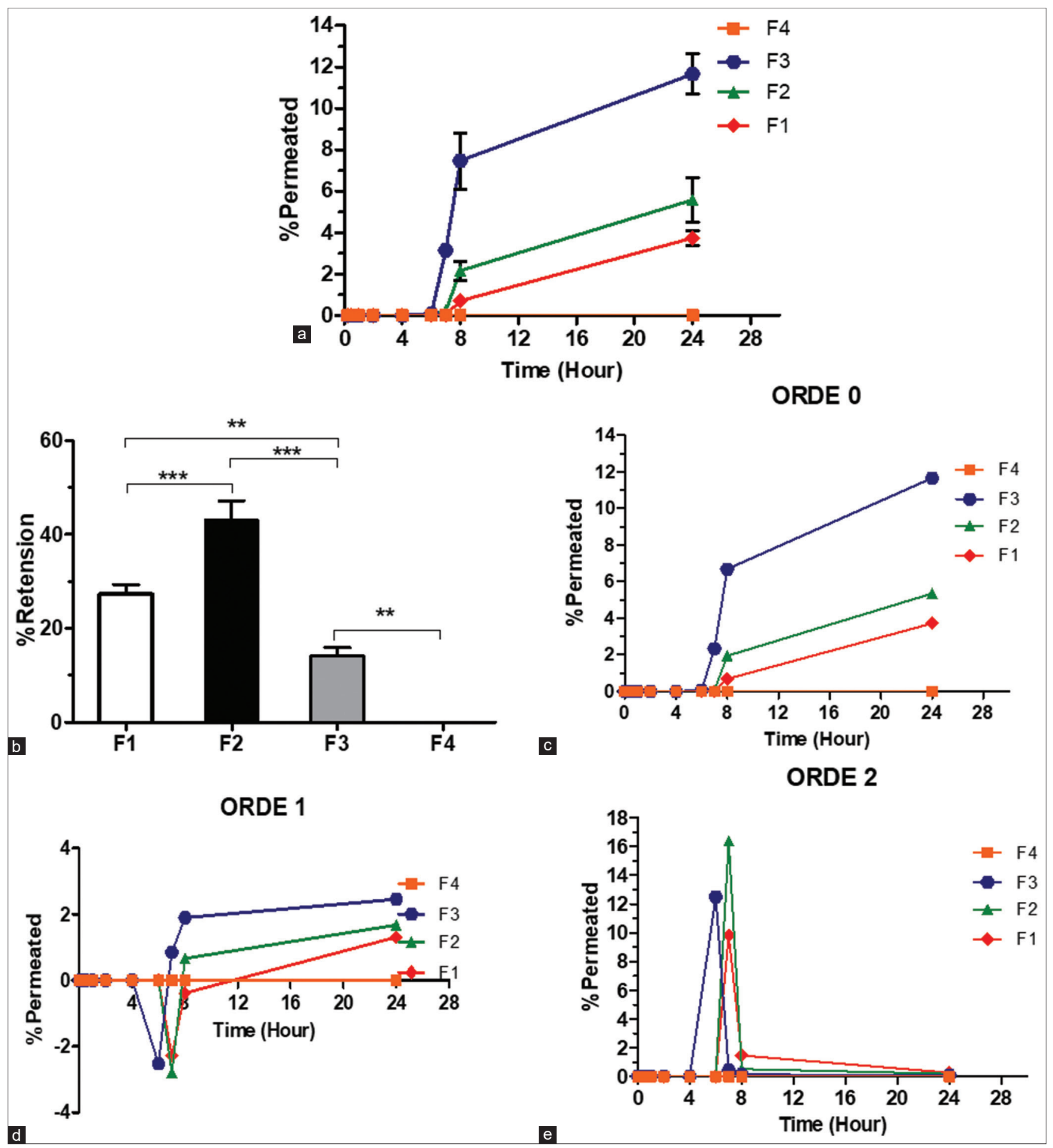

Figure 6: Graph of permeation test results (a), histogram of retention test results (b), graph of drug release kinetics order 0 (c), the graph of drug release kinetics 1 (d), and graph of drug release kinetics 2 (e) 
in the formula. Then the number of percent's permeated at the $24^{\text {th }} \mathrm{h}$ in a row was $3.74 \% ; 5.58 \%$; and $11.67 \%$. Furthermore, the permeability coefficient parameter also shows a significant SD between each nanoemulgel formula. The coefficient of permeability $(P)$ is a value that indicates the rate of penetration of caffeic acid through the skin, and its value was determined at steady-state flux. The variability of these results can be caused by several things, such as the composition, nanoemulgel's volume, and the surface area of the skin. In addition, it also depends on the characteristics of the skin used. The greater the permeability coefficient $(P)$ value means that the easier the compound is to penetrate the skin. It can be seen in Table 6.

Based on the amount of permeation F1, F2, and F3 containing permeation enhancers, it was seen that the concentration of oleic acid was able to increase the amount of drug that permeated into the skin. Therefore, as the concentration of oleic acid increases, the number of drugs that can permeate through the membrane increases. Statistical analysis using the One-Way ANOVA test on the four nanoemulgel formulas showed a significant difference in each formula $p$-value was $0.0470(p<0.05)$. Furthermore, the post hoc test using Tukey's Multiple Comparison Test method, to find out which variants were significantly different, the results obtained showed that the comparison between F1, F2, and F3 nanoemulgel did not have a significant difference $(p>0.05)$, for F3 and F4 have a significant difference $(p<0.05)$.

\section{Retention test}

The permeation data do not fully support the desired local effect because the permeation test was carried out to determine the amount of drug that can enter the skin, while to achieve the local effect, it was necessary to know the amount of caffeic acid that can be left on the skin so that a retention test was carried out. The results of the nanoemulgel retention test can be seen in the histogram above. In the histogram, it can be seen that F1 has a lower amount of caffeic acid deposited than F2, with a $1.25 \%$ oleic acid concentration. It indicates that $\mathrm{F} 1$ does not have a high retention time on the skin. The highest amount of caffeic acid deposited after $24 \mathrm{~h}$ was found in F2 with a concentration of $2.5 \%$ oleic acid, which indicates that $\mathrm{F} 2$ has a high retention time to provide local effects on the skin. F3, which contains oleic acid with a concentration of $5 \%$ and has a higher amount of permeation, shows a lower amount of retention than $\mathrm{F} 1$ and $\mathrm{F} 2$; this indicates that a higher concentration of oleic acid can permeate well but does

Table 6: Result of percent permeated, steady-state flux, and Permeation coefficient (mean $\pm S D, n=3$ )

\begin{tabular}{llll}
\hline Formula & Permeated $(\%)$ & Steady-state flux $\left(\mu \mathrm{g} / \mathrm{cm}^{2} \mathrm{~s}\right)$ & Permeation coefficient $\left(\mathrm{cm}^{2} / \mathrm{s}\right)$ \\
\hline F1 & 3.74 & 0.36 & $3.14 \times 10^{-3}$ \\
F2 & 5.58 & 0.54 & $4.89 \times 10^{-3}$ \\
F3 & 11.67 & 1.13 & $9.98 \times 10^{-3}$ \\
F4 & 0 & 0 & 0 \\
\hline
\end{tabular}

not have a high retention time. In the skin, it directly reaches the systemic circulation and does not provide the desired local effect. One of the importances of the dermal drug delivery system is that it can maximize the amount of drug that enters the skin layer to increase the residence time of the drug in the skin.

Statistical analysis using the One-Way ANOVA test on each nanoemulgel formula showed a significant difference in the retention test results $p<0.0001$ ( $p<0.05)$. Furthermore, the post hoc test using Tukey's Multiple Comparison Test method, the results obtained indicate that the four formulas have significant differences $(p<0.05)$. Based on these results, if $\mathrm{F} 2$, which has an oleic acid concentration of $2.5 \%$, shows good retention results on the skin, compared to a concentration of $1.25 \%$ oleic acid (F1) or an oleic acid concentration of $5 \%$ (F3) has a significant difference in the results of the retention test.

\section{Drug release kinetics}

Drug release kinetics can describe the rate of drug release and its release model. In this zeroorder system, drug release occurs at a constant rate, independent of concentration. First-order release kinetics can be obtained by plotting the logarithm of the cumulative percent of drug remaining against time. The rate of release in this system is concentrationdependent. The rate at any given time is proportional to the concentration of the drug remaining in the preparation at that time. The release kinetics of the Higuchi model can be obtained by plotting the cumulative percent drug release against the root of time.

The profile of the release model of nanoemulgel can be seen by referring to the linear regression value close to 1. Comparison of the release kinetics of the formula with the comparison of the coefficient of determination $\left(R^{2}\right)$ is shown in Table 7 and Figure 6 . The overall drug release model meets the release model of zero-order, so it can be concluded that the release of caffeic acid in nanoemulgel occurs at a constant rate, independent of concentration.

Table 7: Linearity coefficient of release kinetics model

\begin{tabular}{llll}
\hline Formula & \multicolumn{3}{l}{ Linearity coefficient of release kinetics model $\left(\mathrm{R}^{2}\right)$} \\
\cline { 2 - 4 } & Zero-order & First Order & Higuchi \\
\hline F1 & 0.9044 & 0.1882 & 0.0101 \\
F2 & 0.8825 & 0.1559 & 0.0098 \\
F3 & 0.8657 & 0.3441 & 0.0021 \\
F4 & 0 & 0 & 0 \\
\hline
\end{tabular}

\section{Conclusion}

This study investigated the potential of oleic acid on the nanoemulgel delivery system to increase the penetration of caffeic acid, the active compound 
of propolis that has anti-inflammatory activity. The maceration used $70 \%$ ethanol was obtained $6.037 \pm$ $1.27 \mathrm{mg} / \mathrm{g}$ of caffeic acid. Several evaluations were carried out to determine the effect of oleic acid on the physical characteristics and stability of the four formulas, which had significant differences $(p<0.05)$ on particle size, Pdl, spreadability, adhesion, and the freeze-thaw test. There was no significant difference $(p>0.05)$ to the $\mathrm{pH}$ of nanoemulgel, which shows a $\mathrm{pH}$ of about $5-6$, which was very close to the skin $\mathrm{pH}$ so that there was no possibility of skin irritation and viscosity at the beginning formation and after 4 weeks of storage and zeta potential test $> \pm 30 \mathrm{mV}$ which indicates a stable formula. The permeability of nanoemulgel was also evaluated, showing that $\mathrm{F} 3$ with $5 \%$ oleic acid had a significantly higher permeation power than F1, F2, and F4. Utilizing a nanoemulgel delivery system proves the principle for enhanced permeation and absorption of lipophilic compounds such as caffeic acid. Furthermore, the retention power of nanoemulgel was reviewed. The results showed that F2 was the formula with the most optimal retention amount with a percentage of $43.13 \%$ at $24 \mathrm{~h}$, the increase in skin retention after administration of nanoemulgel showed the higher caffeic acid to inhibit inflammation in the skin, and all formulas tended to follow order 0 drug release kinetics. Thus, it can be concluded that the developed nanoemulsionbased gel has a more significant potential for topical drug delivery for skin penetration. However, further extensive investigations are needed, including studies of inflammation, toxicity, and in vivo pharmacodynamic studies in suitable animal models.

\section{Acknowledgments}

This study was supported by pharmacy faculty in Pharmaceutics Laboratory and Biopharmaceutical Laboratory. The authors thank Mrs. Dewi Primayanti and Mrs. Sumiati for helpful during the formulation and evaluation of the nanoemulgel.

\section{References}

1. Silva-Carvalho R, Baltazar F, Almeida-Aguiar C. Propolis: A complex natural product with a plethora of biological activities that can be explored for drug development. Evid Based Complement Altern Med. 2015;2015:206439. https://doi. org/10.1155/2015/206439

PMid:26106433

2. Tiveron AP, Rosalen PL, Franchin M, Lacerda RC, Bueno-Silva B, Benso $\mathrm{B}$, et al. Chemical characterization and antioxidant, antimicrobial, and anti-inflammatory activities of South Brazilian organic propolis. PLoS One. 2016;11(11):e0165588. https://doi. org/10.1371/journal.pone. 0165588

\section{PMid:27802316}

3. Bittencourt ML, Ribeiro PR, Franco RL, Hilhorst HW, de Castro RD, Fernandez LG. Metabolite profiling, antioxidant and antibacterial activities of Brazilian propolis: Use of correlation and multivariate analyses to identify potential bioactive compounds. Food Res Int. 2015;76(Pt 3):449-57. https://doi. org/10.1016/j.foodres.2015.07.008

PMid:28455025

4. Pasupuleti VR, Sammugam L, Ramesh N, Gan SH. Honey, propolis, and royal jelly: A comprehensive review of their biological actions and health benefits. Oxid Med Cell Longev. 2017;2017:1259510. https://doi.org/10.1155/2017/1259510 PMid:28814983

5. Santana HF, Barbosa AA, Ferreira SO, Mantovani HC. Bactericidal activity of ethanolic extracts of propolis against Staphylococcus aureus isolated from mastitic cows. World J Microbiol Biotechnol. 2012;28(2):485-91. https://doi. org/10.1007/s11274-011-0839-7

PMid:22806843

6. Rufatto LC, Luchtenberg P, Garcia C, Thomassigny C, Bouttier S, Henriques JA, et al. Brazilian red propolis: Chemical composition and antibacterial activity determined using bioguided fractionation. Microbiol Res. 2018;214:74-82. https:// doi.org/10.1016/j.micres.2018.05.003

PMid:30031483

7. Wagh VD. Propolis: A wonder bees product and its pharmacological potentials. Adv Pharmacol Sci. 2013;2013:308249. https://doi.org/10.1155/2013/308249 PMid:24382957

8. Šuran J, Cepanec I, Mašek T, Radi B. Propolis extract and its bioactive compounds from traditional to modern extraction technologies. Tradit Mod Extra Technol. 2021;26(10):2930. PMid:34069165

9. Da Cunha FM, Duma D, Assreuy J, Buzzi FC, Niero R, Campos MM, et al. Caffeic acid derivatives: In vitro and in vivo anti-inflammatory properties. Free Radic Res. 2004;38(11):124153. https://doi.org/10.1080/10715760400016139 PMid: 15621702

10. Žilius M, Ramanauskiene $\mathrm{K}$, Briedis V. Release of propolis phenolic acids from semisolid formulations and their penetration into the human skin in vitro. Evid Based Complement Altern Med. 2013;2013:958717. https://doi.org/10.1155/2013/958717

11. Butnariu MV, Giuchici CV. The use of some nanoemulsions based on aqueous propolis and lycopene extract in the skin's protective mechanisms against UVA radiation. J Nanobiotechnol. 2011;9:3. https://doi.org/10.1186/1477-3155-9-3

12. Fathi M, Mirlohi M, Varshosaz J, Madani G. Novel caffeic acid nanocarrier: Production, characterization, and release modeling. Nanomaterials. 2013;2013:434632. https://doi.org/ http://dx.doi.org/10.1155/2013/434632

13. Seo YS, Cha S, Cho S, Yoon H, Kang Y, Park Y. Caffeic acid: Potential applications in nanotechnology as a green reducing agent for sustainable synthesis of gold nanoparticles. NPC Natural Product Commun. 2015;10(4):627-30. https://doi. org/10.1177/1934578X1501000424 PMid:25973494

14. Lin Q, Huang H, Chen L, Shi G. Synthesis of caffeic acid coated silver nanoparticles for the treatment of osteoarthritis. Biomedical Research. 2017;28(3):1276-9.

15. Chen H, Khemtong C, Yang X, Chang X, Gao J. Nanonization strategies for poorly water-soluble drugs. Drug Discov Today. 2011;16:354-60. https://doi.org/10.1016/j. drudis.2010.02.009 PMid:20206289

16. Lovelyn C, Attama AA. Current state of nanoemulsions in drug delivery. J Biomater Nanobiotechnol. 2011;2:626-39. https://doi. 
org/10.4236/jbnb.2011.225075

17. Eid AM, El-Enshasy HA, Aziz R, Elmarzugi NA. Preparation, characterization and anti-inflammatory activity of Swietenia macrophylla nanoemulgel. J Nanomed Nanotechnol. 2014;5:2. https://doi.org/10.4172/2157-7439.1000190

18. Sutradhar KB, Amin L. Nanoemulsions: Increasing possibilities in drug delivery. Eur J Nanomed. 2013;5:97-110. https://doi. org/10.1515/ejnm-2013-0001

19. Chellapa P, Mohamed AT, Keleb El, Elmahgoubi A, Eid AM, Issa $Y S$, et al. Nanoemulsion and nanoemulgel as a topical formulation. IOSR J Pharm. 2015;5(10):43-7.

20. Choudhury H, Gorain B, Pandey M, Chatterjee LA, Sengupta P, Das $A$, et al. Recent update on nanoemulgel as topical drug delivery system. J Pharm Sci. 2017;106(7):1736-51. https://doi. org/10.1016/j.xphs.2017.03.042 PMid:28412398

21. Prajapati B. "Nanoemulgel" innovative approach for topical gel based formulation. Res Rev Healthc Open Access J. 2018;1(2):18-23. https://doi.org/10.32474/rrhoaj. 2018.01.000107

22. Devarajan V, Ravichandran V. Nanoemulsions: As modified drug delivery tool. Pharm Glob. 2011;2:1-6.

23. Rahayu N, Mita SR. Efek penggunaan tunggal dan kombinasi asam oleat sebagai penetrasi pada sediaan transdermal. Farmaka. 2014;14:82-92.

24. Hallan SS, Sguizzato M, Drechsler M, Mariani P, Montesi L, Cortesi $\mathrm{R}$, et al. The potential of caffeic acid lipid nanoparticulate systems for skin application: In vitro assays to assess delivery and antioxidant effect. Nanomaterials. 2021;11(1):171. https:// doi.org/10.3390/nano11010171 PMid:33445433

25. Baibhav J, Gurpreet S, Rana A, Seema S, Emulgel VS. A comprehensive review on the recent advances in topical drug delivery. Int Res J Pharm. 2011;2(11):66-70.

26. Khairunnisa K, Mardawati E, Putri SH. Characteristics of phytochemicals and antioxidant activity of propolis extract bees Trigona Sp. J Ind Pertan. 2020;2:124-9.

27. Sartini S, Djide MN, Amir MN, Permana AD. Phenolic-rich green tea extract increases the antibacterial activity of amoxicillin against Staphylococcus aureus by in vitro and ex vivo studies. J Pharm Pharmcogn Res. 2020;8(6):491-500.

28. Spagnol CM, Isaac VL, Corrêa MA, Salgado HR. Validation of HPLC-UV assay of caffeic acid in emulsions. J Chromatogr Sci. 2016;54(3):305-11. https://doi.org/10.1093/chromsci/bmv142 PMid:26499121

29. Rebiai A. Determination of caffeic acid and gallic acid in Algerian bee pollen by an HPLC method. PCBS J. 2014. https://doi. org/10.13140/2.1.5049.9208

30. Gokhale JP, Mahajan HS, Surana SS. Quercetin loaded nanoemulsion-based gel for rheumatoid arthritis: In vivo and in vitro studies. Biomed Pharmacother. 2019;112:108622. https://doi.org/10.1016/j.biopha.2019.108622 PMid:30797146

31. Alam MS, Algahtani MS, Ahmad J, Kohli K, Shafiq-UnNabi S, Warsi $\mathrm{MH}$, et al. Formulation design and evaluation of aceclofenac nanogel for topical application. Ther Deliv. 2020;11(12):767-78. https://doi.org/10.4155/tde-2020-0076 PMid:33225842

32. Mulia K, Ramadhan RMA, Krisanti EA. Formulation and characterization of nanoemulgel mangosteen extract in virgin coconut oil for topical formulation. MATEC Web Conf. 2018;156:01013. https://doi.org/10.1051/ matecconf/201815601013

33. Soliman WE, Shehata TM, Mohamed ME, Younis NS, Elsewedy HS. Enhancement of curcumin anti-inflammatory effect via formulation into myrrh oil-based nanoemulgel. Polymers (Basel). 2021;13:577. https://doi.org/10.3390/polym13040577 PMid:33672981

34. Andonova VY, Peneva PT, Apostolova EG, Dimcheva TD, Peychev ZL, Kassarova MI. Carbopol hydrogel/sorbitan monostearate-almond oil based organogel biphasic formulations: Preparation and characterization of the bigels. Trop J Pharm Res. 2017;16:1455-63. https://doi.org/10.4314/ tjpr.v16i7.1

35. Lala RR, Awari NG. Nanoemulsion-based gel formulations of COX-2 inhibitors for enhanced efficacy in inflammatory conditions. Appl Nanosci. 2014;4:143-51. https://doi. org/10.1007/s13204-012-0177-6

36. Algahtani MS, Ahmad MZ, Ahmad J. Nanoemulgel for improved topical delivery of retinyl palmitate: Formulation design and stability evaluation. Nanomaterials. 2020;10:848. https://doi. org/10.3390/nano10050848

PMid:32353979

37. Kumar S, Prasad M, Rao R. Topical delivery of clobetasol propionate loaded nanosponge hydrogel for effective treatment of psoriasis: Formulation, physicochemical characterization, antipsoriatic potential and biochemical estimation. Mater Sci Eng C. 2021;119:111605. https://doi.org/10.1016/j. msec.2020.111605

PMid:33321649

38. Kaur R, Ajitha M. Formulation of transdermal nanoemulsion gel drug delivery system of lovastatin and its in vivo characterization in glucocorticoid induced osteoporosis rat model. J Drug Deliv Sci Technol. 2019;52:968-78. https://doi.org/10.1016/j. jddst.2019.06.008

39. Barradas TN, Senna JP, Cardoso SA, Nicoli S, Padula C, Santi $\mathrm{P}$, et al. Hydrogel-thickened nanoemulsions based on essential oils for topical delivery of psoralen: Permeation and stability studies. Eur J Pharm Biopharm. 2017;116:38-50. https://doi.org/10.1016/j.ejpb.2016.11.018

PMid:27867112

40. Singh A, Bali A. Formulation and characterization of transdermal patches for controlled delivery of duloxetine hydrochloride. J Anal Sci Technol. 2016;7:25. https://doi.org/10.1186/ s40543-016-0105-6

41. Raj RA. Formulation evaluation and in vitro permeation studies of transdermal nifedipine from matrix type patches. Int J Pharm Pharm Sci. 2014;6:185-8.

42. Attama AA, Reichl S, Christel CM. Diclofenac sodium delivery to the eye: In vitro evaluation of novel solid lipid nanoparticle formulation using human cornea construct. Int J Pharm. 2008;355(1-2):307-13. https://doi.org/10.1016/j. ijpharm.2007.12.007

PMid:18242022

43. Permana AD, Utami RN, Courtenay AJ, Manggau MA, Donnelly RF, Rahman L. Phytosomal nanocarriers as platforms for improved delivery of natural antioxidant and photoprotective compounds in propolis: An approach for enhanced both dissolution behaviour in biorelevant media and skin retention profiles. J Photochem Photobiol B Biol. 2020;205:111846. https://doi.org/10.1016/j.jphotobiol.2020.111846

44. Zhang Y, Huo M, Zhou J, Zou A, Li W, Yao C, et al. DDSolver: An add-in program for modeling and comparison of drug dissolution profiles. AAPS J. 2010;12(3):263-71. https://doi.org/10.1208/ s12248-010-9185-1

PMid:20373062

45. Osés SM, Marcos P, Azofra P, de Pabl A, Fernández-Muíño MÁ, SanchoMT.Phenolic profile, antioxidant capacities and enzymatic inhibitory activities of propolis from different geographical areas: Needs for analytical harmonization. Antioxidants. 2020;9:20-35. https://doi.org/10.3390/antiox9010075 
45. Balata GF, El-Moneom SH, Elmoneim A, Mohamed $\mathrm{H}$ Abdullah HA, Abdulaziz AM. Propolis emulgel: A natural remedy for burn and wound propolis emulgel: A natural remedy for burn and wound. Drug Dev Ind Pharm. 2018;44(11):17971808. https://doi.org/10.1080/03639045.2018.1496449 PMid:29973098

46. Aliyazıcıoglu R, Sahin H, Erturk O, Ulusoy E, Aliyazıcıoglu R, Sahin $\mathrm{H}$, et al. Properties of phenolic composition and biological activity of propolis from Turkey. 2013;2013:2912. https://doi.org /10.1080/10942912.2010.551312

47. Feás X, Pacheco L, Iglesias A, Estevinho LM. Use of propolis in the sanitization of lettuce. Int J Mol Sci. 2014;15(7):12243-57. https://doi.org/10.3390/ijms150712243 PMid:25007823

48. Modestas C, Ramanauskien K, Juškait V, Briedis V. Formulation of propolis phenolic acids containing microemulsions and their biopharmaceutical characterization 2016;2016:8175265. https:// doi.org/10.1155/2016/8175265

PMid:27885330

49. Zarate MS, del Abraham Juárez MR, García AC, López CO, Chávez AJ, de Garfias JJ, et al. Flavonoids, phenolic content, and antioxidant activity of propolis from various areas of Guanajuato, Mexico. Food Sci Technol. 2018;38:210-5. https:// doi.org/10.1590/fst.29916

50. Yuliana ND, Wijaya $\mathrm{CH}$, Nasrullah N. Classification of Trigona spp Bee Propolis from Four Regions in Indonesia Using FTIR Metabolomics Approach. Singapore: $13^{\text {th }}$ Asean Asian Food Conference; 2013. p. 9-11.

51. Salim SA, Saputri FA, Saptarini NM, Levita J. Advantages limitations of folin-ciocalteu reagent in determining total ph levels in plants. Farmaka. 2020;18:46-57.

52. Sánchez-Rangel JC, Benavides J, Heredia JB, CisnerosZevallos L, Jacobo-Velázquez DA. The Folin-Ciocalteu assay revisited: Improvement of its specificity for total phenolic content determination. Anal Methods. 2013;5:5990-9. https://doi. org/10.1039/c3ay41125g

53. Lagouri V, Prasianaki D, Krysta F, Lagouri V, Prasianaki D, Krysta F. Antioxidant properties and phenolic composition of greek propolis extracts composition of greek propolis extracts. Int J Food Properties. 2014;17:511-22. https://doi.org/10.1080/1 0942912.2012 .654561

54. Arianto A, Lie DY, Sumaiyah S, Bangun H. Preparation and evaluation of nanoemulgels containing a combination of grape seed oil and anisotriazine as sunscreen. Open Access Maced J Med Sci. 2020;8:994-9. https://doi.org/10.3889/ oamjms.2020.5293
55. Iradhati $\mathrm{AH}$, Jufri M. Formulation and test of physical stability of griseofulvin gel microemulsion. FF UI J. 2016;2016:60293.

56. Genatrika E, Nurhikmah I, Hapsari I. Formulation of Black Cumin Oil Cream Preparation (Nigella sativa L.) as an anti acne against propionibacterium acnes bacteria. Pharmacy.2016;13:192-201.

57. Sanaji JB, Krismala MS, Liananda FR. Pengaruh Konsentrasi Tween 80 Sebagai Surfaktan Terhadap Karakteristik Fisik Sediaan Nanoemulgel Ibuprofen The Effect Of Tween 80 Concentration As A Surfactant On Nanoemulgel Ibuprofen's Physical Characteristics; 2019.

58. Khurana S, Jain NK, Bedi PM. Nanoemulsion based ge for transdermal delivery of meloxicam: Physico-chemical, mechanistic investigation. Life Sci. 2013;92(6-7):383-92. https:// doi.org/10.1016/j.lfs.2013.01.005 PMid:23353874

59. Gupta A, Eral HB, Hatton TA, Doyle PS. Nanoemulsions: Formation, properties and applications. $\mathrm{R}$ Soc Chem. 2016;12:2826-41. https://doi.org/10.1039/c5sm02958a

60. Wahyuningsih I, Putranti W. Optimization of tween 80 and polyethyleneglikol 400 comparison in self nanoemulsifying drug delivery system (SNEDDS) formula of black cumin seed oil. Pharmacy. 2015;12:223-41.

61. Mao $\mathrm{Y}$, Chen $\mathrm{X}, \mathrm{Xu} \mathrm{B}$, Shen $\mathrm{Y}, \mathrm{Ye} \mathrm{Z}$, Chaurasiya B, et al. Eprinomectin nanoemulgel for transdermal delivery against endoparasites and ectoparasites: Preparation, in vitro and in vivo evaluation. Drug Deliv. 2019;26:1104-14. https://doi.org/ 10.1080/10717544.2019.1682720

PMid:31735104

62. Honary S, Zahir F. Effect of zeta potential on the properties of nano-drug delivery systems a review (Part 1). Trop J Pharm Res. 2013;12:255-64.

63. Júnior JA, Baldo JB. The behavior of zeta potential of silica suspensions. N J Glass Ceramics 2014;4:29-37.

64. Mukhlishah NR, Sugihartini N, Yuwono T. Irritation test and physical properties of unguentum volatile oil of Syzygium aromaticum in hydrocarbon base. Maj Farm 2016;12:255-71, 607-8.

65. Shan WY, Wicaksono IA. Formulasi Gel Ekstrak Kulit Manggis (Garcinia mangostana) Dengan Variasi Konsentrasi Basis. Farmaka. 2018;16:108-16.

66. Sulistyaningsih, Gozali D, Bambang RM, Mustarichie R. Ketoconazole emulgel formula activity test against Microsporum gypseum and Candida albicans. J Pharm Sci Res. 2017;9:2458-62.

67. Rowe RC, Sheskey PJ. Handbook of Pharmaceutical Excipients. $6^{\text {th }}$ ed. London: The Pharmaceutical Press; 2009. 